\title{
THEORETICAL PERSPECTIVES ON RESILIENCE AND SUSTAINABILITY IN TRANSPORTATION AND SPATIAL PLANNING
}

\author{
C. B. SCHOEMAN \\ Unit for Environmental Sciences and Management, \\ North West University (Potchefstroom Campus), South Africa.
}

\begin{abstract}
The debate on sustainability and resilience is dealt with by many authors working within the environmental, ecological and human settlement planning domains. These concepts and its interface can hardly be separated form the core focuses and processes involved in transportation and spatial planning as related disciplines. The terminology of resilience developed before the 1970's whilst the debate on environmental sustainable development were formalized in the period 1972 to 1992 . However, from a literature assessment perspective, the concepts are used and applied differently and sometimes interchangeably within both the 'soft' and 'hard' components involved in various disciplines and professions. The purpose of this paper is to focus on the founding theoretical perspectives underpinning resilience and sustainability and to apply it to the strategic approaches, focuses and instruments used in transportation and spatial planning and development. Mainstreaming of resilience and sustainability is essential as it concerns the core focuses of urban and rural development. Planning implies short, medium and long term strategies, policies and principles applied through instruments/tools with the goal and objective to plan and ensure resilience and sustainability in spatial systems. These are core considerations in transportation and spatial planning that need to be dynamic with the ability to accommodate change, socio-economic, ecological, physical and natural issues and challenges.

Keywords: resilience, spatial planning, sustainability, transport.
\end{abstract}

\section{INTRODUCTION}

Although researchers argue that a city can be sustainable, Elmqvist [1] states that the answer is no. He points out that cities are centres of production and consumption and that inhabitants are reliant on sources and ecosystems services from food, water, construction materials to waste assimilation, secured from locations all over the world. Cities are thus by implication globally integrated. 'Although cities can optimize their resource use, increase their efficiency, and minimise waste, they can never become fully self-sufficient'.

Increasing economic, social and spatial vulnerabilities in cities; the rapid depletion of natural resources, necessitating resource management; and the increasing frequency of ecological events and other causes of environmental degradation implies the necessity to open discussions on the term resilience and to adopt resilience thinking in planning as illustrated by Eraydin and Taşan-Kok [2]. These concepts and its interface can hardly be separated form the core focuses in theory, processes and practices supporting transportation and spatial planning as interrelated disciplines.

The terminology of resilience dates back to before 1970's whilst the debate on environmental sustainable development were founded in the period 1972 to 1992 [3]. Olazabal et al. [4] states that urbanization is a central driver of global environmental change. Consequently, it is essential that urban policies and planning align to address both regional (within spatial systems) and global environmental problems.

The purpose of this paper is to focus on founding theoretical perspectives underpinning resilience and sustainability based on strategic approaches, focuses and instruments as applied 
in transportation and spatial planning. Mainstreaming of resilience and sustainability is essential as it is fundamental to the supportive components in planning and development. Planning implies short, medium and long term strategies, policies and principles through application of instruments/tools with the goal and objective to deliver on resilience and sustainability.

\section{CONCEPT OF RESILIENCE VERSUS SUSTAINABILITY}

Harrison, et al. [5] point out that the ideas and principles outlined in the relationship between sustainability and resilience are supported by the theory underlying socio-ecological resilience.

\subsection{The concept of resilience}

In the light of the diversity of interpretations and applications of the resilience concept in urban spatial systems Olazabal et al. [4] attempt to offer an integrated view on resilience research. In their understanding the concept of 'urban resilience' goes beyond its widespread application in the climate protection arena (sustainability). They use various case studies to suggest that urban resilience can be conceived as a multidisciplinary framework to analyse reactive, adaptive and transformative capacities of urban systems and thus spatial systems.

As far as definitions are concerned, they point out that according to the ecological definition of resilience, it is inter alia defined as the magnitude of disturbance that can be absorbed before the system changes its structure by changing the variables and processes that control behaviour. This is demonstrated in terms of a multidisciplinary relationship as illustrated in Fig. 1.

Based on the interpretation that urban resilience is a multidisciplinary concept which allows exploring the dynamics of the city (spatial systems) in different ways, case studies

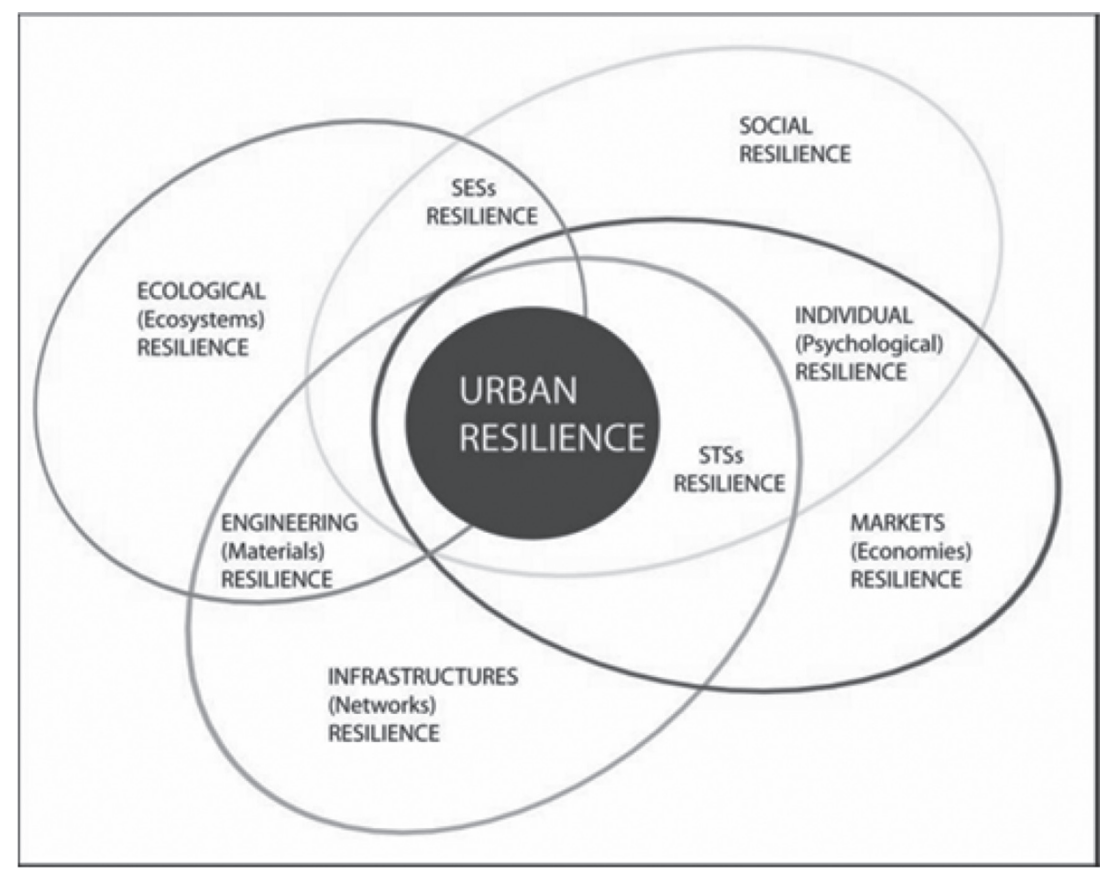

Figure 1: A multidisciplinary perspective of urban resilience (Source: Olazabal et al. [4]). 


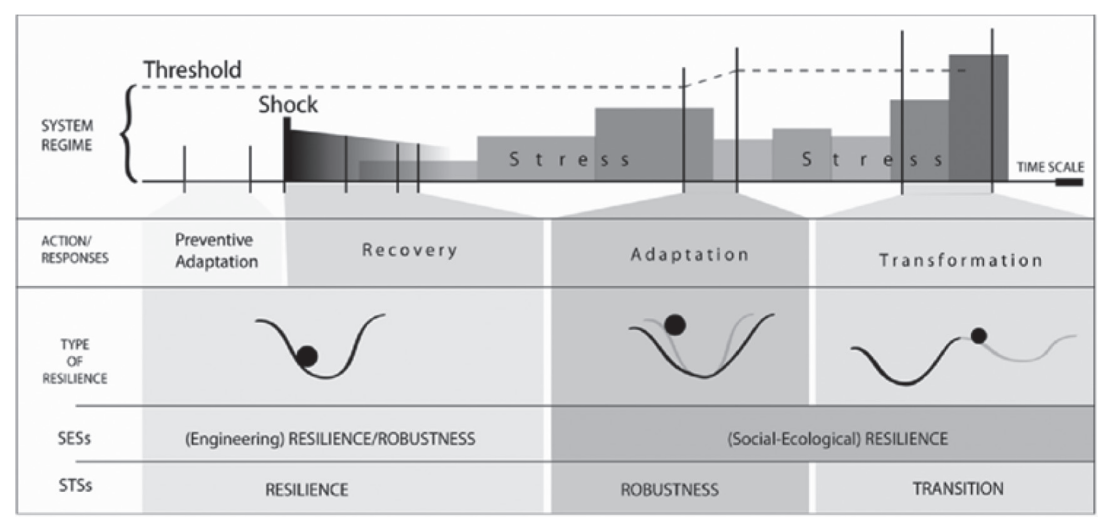

Figure 2: Impact of temporal scale in urban spatial systems (Source: Olazabal et al. [4]).

depict some preliminary findings on the dimensions of the concept. They conclude that in dealing with urban resilience the spatial and temporal scales should be defined in order to clarify the purpose of managing urban resilience. Figure 2 demonstrates the impact of temporal scale in urban spatial systems following an incident related to a shock or impact.

Such a shock is being dealt with by making punctual or progressive adjustments to the urban system (or sub-systems) at operational or structural (spatial) level as applicable to the theme of this paper. They point out that urban resilience consists of a framework to explore the reactive, recovery and adaptive capacities and transformability of urban systems [4].

Meerow et al. [6] state that fostering resilience in the face of environmental, socioeconomic, and political uncertainty and risk has captured the attention of academics and decision makers across disciplines, sectors, and scales. Resilience thus has become an important goal for cities and all spatial systems, particularly in the light of climate change (thus sustainability). From research of scholarly literature on urban resilience they conclude that the term has not been well defined [6]. The existing definitions are inconsistent and underdeveloped with respect to incorporation of crucial concepts found in both resilience theory and urban planning theory. They propose the following definition for urban resilience: 'Urban resilience refers to the ability of an urban system and all its constituent socio-ecological and sociotechnical networks across temporal and spatial scales to maintain or rapidly return to desired functions in the face of a disturbance, to adapt to change, and to quickly transform systems that limit current or future adaptive capacity'.

\subsection{The concept of sustainability}

The United Nations (2010) [7] states that sustainable development is generally accepted as a convergence between the three pillars of economic development, social equity and environmental protection. Over the first 20 years (actually 23 years since Brundtland [8] in 1987) of ongoing debate the concept of sustainable development has often been compartmentalized as an environmental issue only. On the other end of the scale is the more limiting generalization that the orientation of development purely focus on economic growth. There is a huge gap between multilateral processes, consisting of broad goals and policies, national actions (scale) representing domestic political and economic realities. Sustainable development is 
described as the needs of the present without compromising the ability of future generations to meet their own needs [8].

Elmqvist [1] points out that sustainability is commonly misunderstood as being equal to self-sufficiency although in a globalized world, nothing at local scale is self-sufficient. He points out that to be meaningful, urban sustainability has to be viewed in in terms of appropriate scales. Harrison et al. [5] conclude that sustainability and resilience are conceptually linked, but that they are not equivalent in meaning. There is thus no reason why resilience and sustainability cannot co-exist as concepts.

In terms of the focus of this paper resilience thus refers to planning and development goals, objectives and projects that are measurable in terms of qualitative and quantitative yardsticks and analysis. On the other hand, sustainability refers to the broader spatial system contexts that (from a strategic management perspective) are associated with the vision and mission at larger spatial scales (national and regional entities).

Resilience and sustainability depends on local and regional relationships and the ability of such systems to absorb various disturbances and to reorganise itself [2]. Harrison et al. [5] concludes that following the introduction of resilience theory to systems that include human life, a number of scholars have identified cities as examples of complex, adaptive socio-ecological systems. They point out that 'A city may be regarded as a panarchy of sorts, with a nested set of neighbourhoods, suburbs, urban nodes and metropolitan regions'. It may also be regarded as a level within a mega-settlement panarchy $[9,10]$ that extends from small villages to a global urban network (systems at various and different scales). Holling [9] introduced the concept of resilience in 1973 and it is thus not new to the existing body of knowledge.

Davoudi [11] offers an alternative view and critique related to the resilience theory. $\mathrm{He}$ concludes that resilience theory provides a useful framework for understanding the complex interplays between persistence, adaptability and transformability that demonstrates the potential to become a bridging concept between the natural and social sciences. Harrison et al. [5] further note that one should also take account of the critique levelled at resilience theories inclusive of the role of power and politics in shaping the way in which resilience is applied. Resilience theory is partial and needs to be informed by theories from the social sciences that offer critical insights into the ways in which human society functions. Several other social scientists examined the link between social-ecological systems [12-15] and institutional and organizational arrangements $[16,17]$ that is fundamental to the theme of this paper.

\subsection{Meaning of resilience from an urban and spatial form perspective}

Harrison et al. [5] deduced the research themes (focuses) based on the work developed by the Resilience Alliance [18]. They states that the spatial meaning of resilience thus consists of metabolic flows (production, supply and consumption chains), social dynamics (demographics, human capital and inequality), governance networks (institutional structures and organisations) and the built environment (ecosystem services in urban landscapes). This context thus applies to both transportation and spatial planning inclusive of green, brown and blue approaches and contexts.

The benefit of the theory of resilience is that it was developed in ecological research and that it is applicable to socio-ecological systems, including cities and other spatial systems. Resilience thus points towards an understanding of the interactions across scales; the position of cities within a wider systems approach; the interdependencies between natural, technical and social networks inclusive of learning and innovation. 


\section{RESILIENCE THINKING IN SPATIAL PLANNING}

\subsection{Resilience thinking as an approach for planning}

Eraydin and Taşan-Kok [2] state that their research attempts to decipher the concept of resilience in urban policies and planning and endeavours to develop typologies of cities and its developmental trajectories based on social, economic and ecological resilience. Considering the most common problems currently being faced in urban areas, promoting changes in policies and planning through resilience thinking, is extremely important.

They conclude that there is an urgent need to introduce a new planning paradigm since existing planning systems have experienced difficulties in preparing urban areas (spatial systems) to cope with increasing economic, social and ecological pressures and disturbances. A new way of thinking (Fig. 3) is developed to guide and assess the integration of planning processes.

Resilience thinking shows an efficacy for understanding, managing and governing complex linked systems of people and nature [2]. This view is based on the work of Folke et al. [19]. Presently, resilience is not only confined to academic discourses as it has become prevalent in urban policy documents on a global level as well as in practical terms. Resilience as notion enables analysts and decision makers to identify the likelihood of shifts and transitions among different system configurations as illustrated by Peterson [20].

\subsection{Spatial and development relationships and its impact on spatial planning.}

Resilience thinking form the basis of an alternative spatial planning approach implying a reconsideration of the 'substance' of planning within a process that is to focus on 'value systems and power relations' in decision making. This premise is based on the following realties in development within spatial systems:

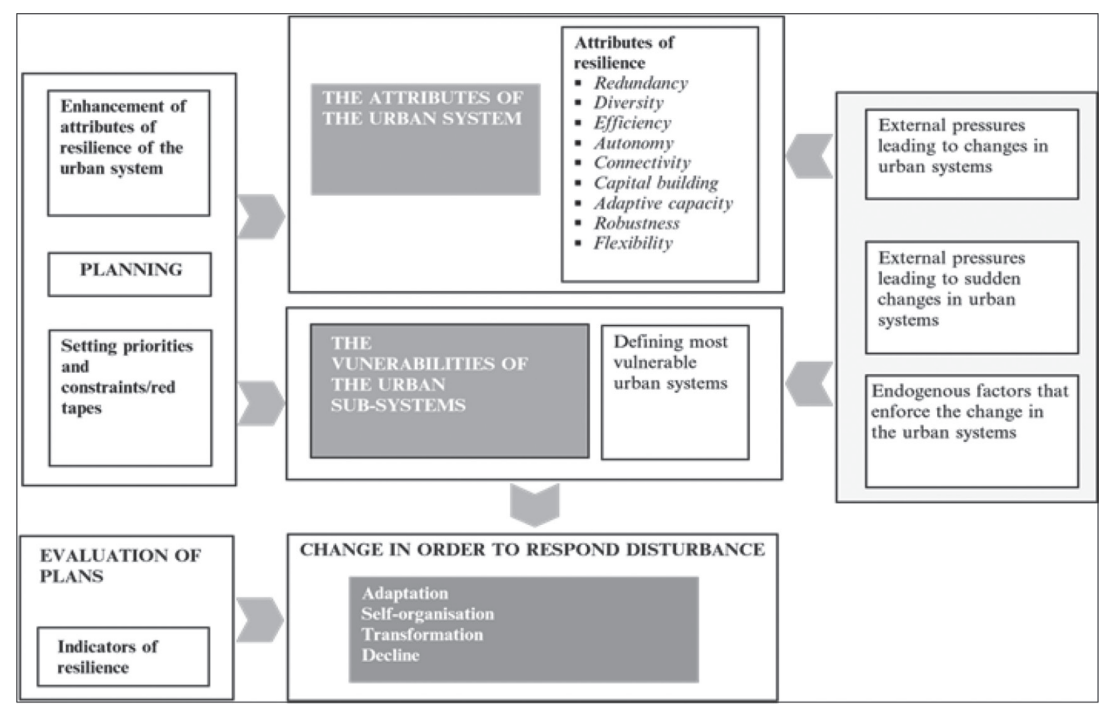

Figure 3: A framework for resilience thinking in spatial planning (Source: Eraydin and Taşan-Kok [2]). 
Eraydin and Taşan-Kok [2] attempt to assess how well equipped contemporary planning theory and practice is in preparing urban areas (spatial systems) to face the new challenges that have resulted from the neoliberal spatial agenda in an increasingly borderless world. Its ability to address the escalating numbers of hazards, most of which are triggered by rising levels of consumption, are thus a core focus. The characteristics of a new theoretical approach to planning may assist in the creation of resilient cities and spatial systems that are able to adapt to both slow changes and major development pressures through transdisciplinary planning. The literature guiding urban areas have become increasingly vulnerable to the outcomes of economic restructuring under the neoliberal political economic ideologies of recent decades. The increased frequency and widening diversity of problems have made it evident that the socio-economic and spatial policies and practices introduced under the neoliberal agenda can no longer be sustained.

Talvitie [21] points out that one major aspect of current spatial development trends can be identified to be the changing nature of advanced societies' economic base, where knowledge and skills are becoming the most important factors in production. He states that fundamental economic change moreover envisages a whole host of new functional and organisational possibilities. The traditional ways of running businesses in industry, services and other organisations, as well as the activities of everyday life, within spatial systems undergo a process of fundamental change. These developments moreover will have a diversified spatial impact accordingly to Plummer et al. [22].

Wilkinson [23] focuses on exploring the potential of social-ecological resilience to inform urban governance in theory and practice, through the process of strategic spatial planning. Strategic spatial planning is viewed as an established urban governance policy tool that articulates government policy regarding land use and development around metropolitan regions. She illustrates how social-ecological resilience as a field of research focuses on how linked social-ecological systems can be applied to government in face of disturbance whilst maintaining the capacity for adaptation, learning and transformation.

Fleischhauer [24] explores the challenges for dealing with risks from a spatial perspective. He points out that planning can play an important role in mitigating multi-hazards by influencing planning and thus strengthening urban resilience. The limits of spatial planning should be taken into account, inclusive of the variety of authorities dealing with multi-hazards such as earthquakes, coastal, river floods and nuclear power plant accidents with threatening consequences for spatial and transportation planning.

Pissourios [25] discusses the ways that the top-down and the bottom-up processes influenced the utilization of planning processes over time. He concludes that the political aspect of planning and the political role of planners have not been emphasized by the planning theories of the 1960s and the early 1970s, with particular regard to the systems view and the rational process of planning. Planning was approached mainly as a technocratic procedure of urban intervention. In response to these procedural perspectives, since the mid-1970s, planning theory has viewed urban planning mainly to be a political discourse only. The launch of the communicative approach in the 1990s took this perspective to its extreme, tending to equate urban planning to politics and to deduce planning theory to be part of political theory. Parallel to and highly correlated with the above transition in planning theory's interest there was the shift from a top-down to a bottom-up approach in urban planning [25].

Healey [26] concludes that two main tendencies have marked the history of spatial planning over the past 50 years. On the one hand there has been a tendency towards centralism and de-politicizing decision-making as well as increasing the role and power of technical experts. On the other hand there have been demands for more participation in decisionmaking (bottom-up approaches based on the postmodern and communicative practices) that 
have provoked the interest of the academic community during the last three decades, although their impact on planning practice were restricted.

From the perspective of this paper, transportation systems/networks are basic to principles underpinning all spatial, urban and regional planning theories and vice versa. This interface also culminates in the integration between land use and transport. The fact that spatial organization theories deals with spatial systems, transportation is core to spatial integration in terms of a systems planning and development approach as discussed above.

3.3 Evolution of resilience thinking and influences impacting on spatial planning and development

Eraydin and Taşan-Kok [2] conclude that a new perspective referred to 'resilience planning' in cooperation with several other actors and role players need to be developed. Meerow et al. [6] illustrates in Fig. 4 the complexities of urban systems impacting on planning and development processes underpinning this challenge.

\section{ROLE OF ADAPTIVE MANAGEMENT IN SPATIAL SYSTEMS}

The most influential ecological interpretation (and thus for spatial planning and development in terms of the theme of this paper) was developed by Holling [10]. Resilience builds on two radical premises first that humans and nature are strongly linked and is thus co-evolving from a systems approach. Both human and nature should thus be conceived as an integrated and single 'social ecological' and spatially related system. The second statement concerns the long-held assumption (misconception) that systems respond to change and impact in a linear, predictable fashion which is wrong. He uses it to explain the capacity of ecological systems to renew themselves in the context of disturbance. In explaining how a system self-renews, Holling uses two key concepts - the 'adaptive cycle' and 'panarchy' [10]

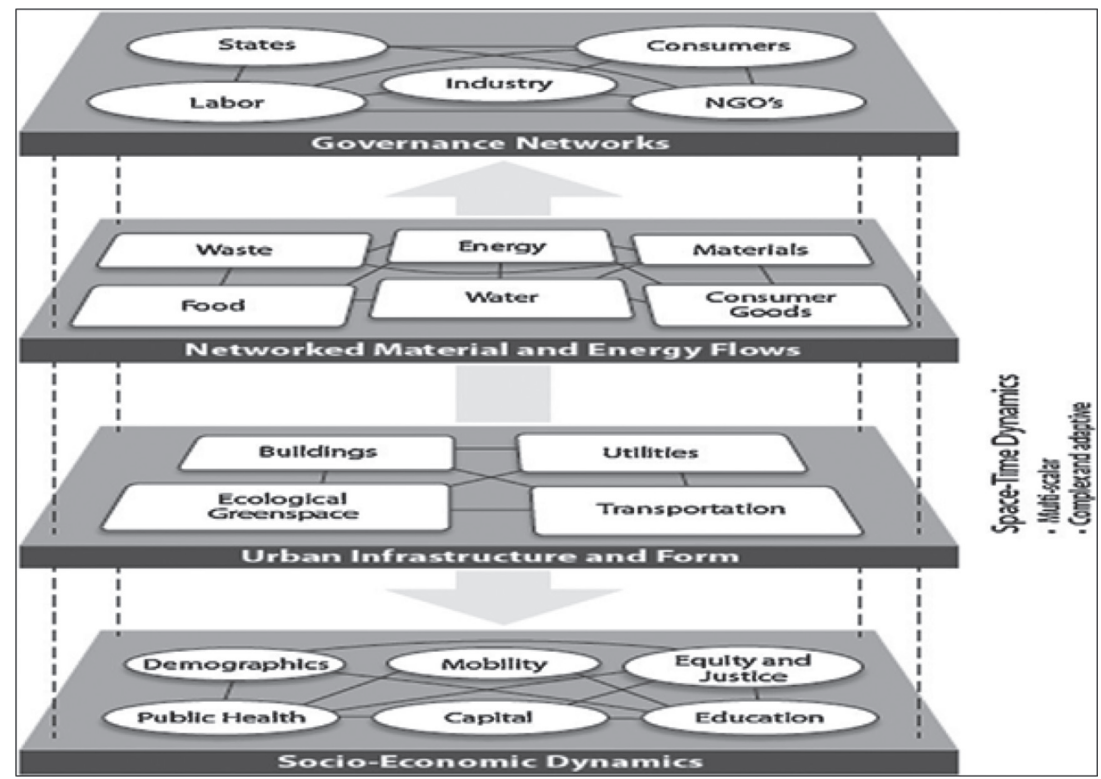

Figure 4: A simplified conceptual schematic of the urban and related spatial systems. (Source: Meerow et al. [6]). 
Harrison et al. [5] point out that the concepts of adaptive governance and adaptive management are related but are not the same. Governance is a wide-ranging term that refers to a network of actors, relationships and processes across scales that assist to co-ordinate or influence action and thus planning in society. Management refers more specifically to processes of monitoring, analysis, supervision, organisation and resource deployment that are necessary to achieve planned goals and objectives.

\section{INTEGRATION BETWEEN PROFESSIONS WITHIN THE PLANNING DOMAIN}

Ahern, Cilliers and Niemela [27] develop an approach to: (1) to explore ways to enhance transdisciplinary and innovative urban planning; (2) to propose a framework for safe-to-fail adaptive urban design - a design concept through which pilot projects can test innovative, but unproven solutions in a responsible and informed manner, with a low risk of failure. The authors argue that the safe-to-fail framework provides an 'alternative structure to integrate' science, professional practice and stakeholder participation. The framework consists of a transdisciplinary working method focussing on steps, actions and actors to align urban ecosystem services into urban and spatial development. In this context the transdisciplinary approach, implying the co-production of knowledge by scientists, planning professionals and spatial system inhabitants is core in realizing the potential of the integrative planning as originally developed by Tress, Tress and Fry [28].

\section{INTEGRATION BETWEEN TRANSPORTATION AND SPATIAL PLANNING PROCESSES FROM A RESILIENCE AND SUSTAINABILITY PERSPECTIVE}

Based on the line of argument and reasoning as dealt with in this paper, the unanswered research question remains how to integrate transportation and spatial planning and development processes as to enhance the notion of resilience and sustainability in various scales of spatial systems in adhering to the theoretical perspectives as discussed? Often planning in general is being associated with strategic planning considerations only. Planning that works need to focus on process, structure and the measurability of output.

Figure 5 illustrates a proposed methodology in addressing the interface between resilience and sustainability underpinning transportation and spatial planning with the objective of resilient project implementation.

The following underlying dynamic concepts are provided for in terms of this model:

- The integration pivots on the interface of resilience and sustainability in transportation and spatial planning thinking, processes and delivery mechanisms for successful and integrated development projects.

- Resilience in this context thus centres on a vertical (resilience) and horizontal (sustainability) axis.

- This approach consist of issues, processes, project and practices and a distinction is made between soft-core and hard core issues planning and development processes.

- Sustainability in this context refers to strategic planning focuses normally associated with broad vision and mission formulation in spatial systems. These are normally measurable from a qualitative perspective.

- Resilience, on the other hand, refers to goals and objectives associated with projects that is measurable in terms of qualitative and quantitative performance, impact and success as evaluation parameters.

- The relationship between resilience and sustainability and more specifically addressing natural and spatial impacts in transportation and spatial planning provides the opportunity to adapt and align the model in terms of local conditions and spatial reality, dynamics and scales. 
- The model as developed is thus scale flexible.

- Provision is made to apply and adapt the model in terms of a systems approach.

\section{CONCLUSIONS}

From the research the conclusion is drawn that theoretical perspectives developed by research scientists and more specifically in the field of urban ecology, proves that professionals such as transportation and spatial planners does not necessarily optimise the interface between theory and practice as far as resilience and sustainability in thinking, approaches, methodologies and project implementation are concerned.

The notion of 'safe to fail' as applied by urban ecologists is viewed to be negative in terms of spatial and transportation planning processes and delivery. It is sometimes wrongly interpreted to be applicable to functionaries in the planning professions specifically and the built environment in general. The alternative is a focus to be successful through forward and backward linkages in terms of dynamic transdisciplinary planning methodology as developed in this paper (Fig. 5).

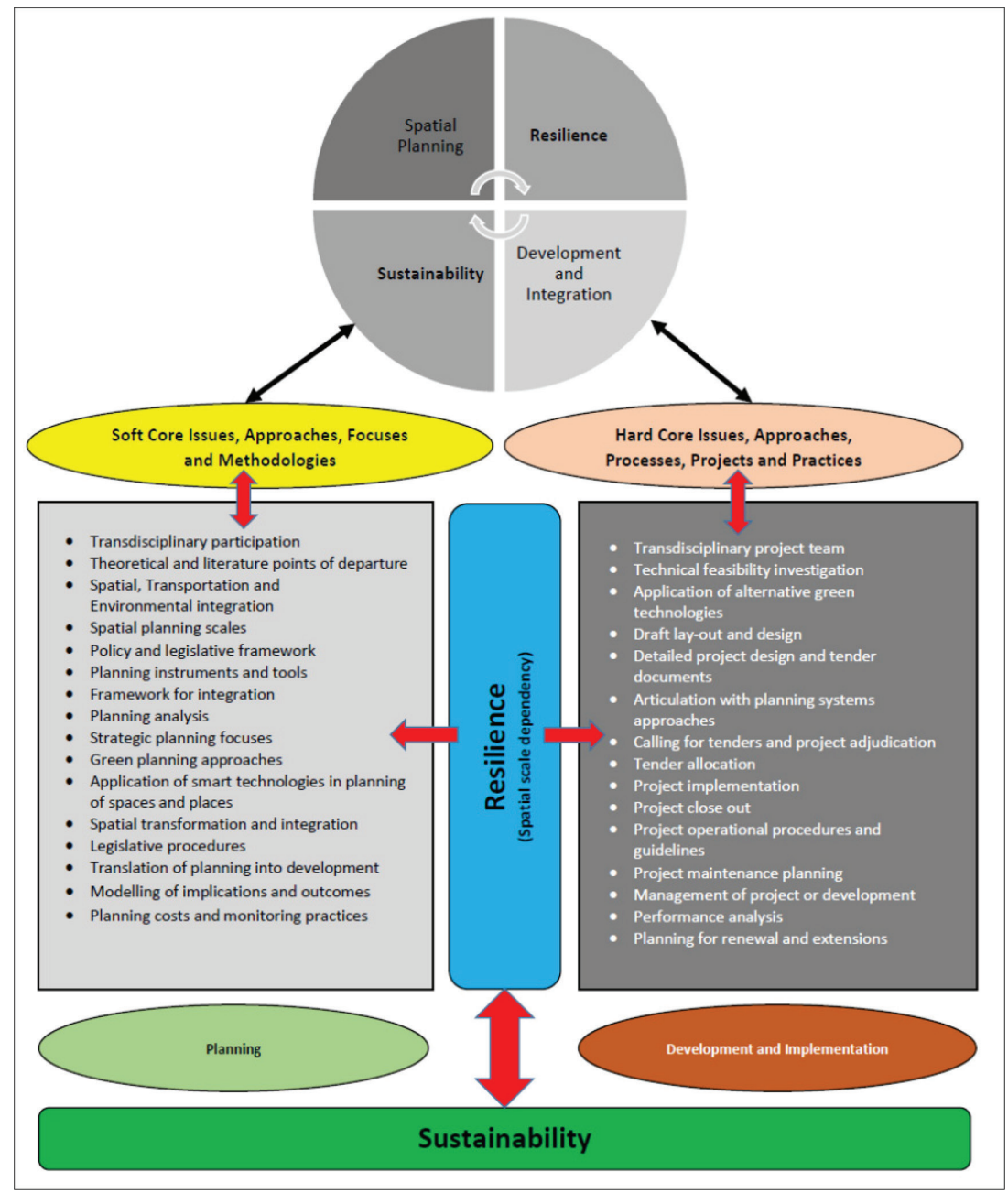

Figure 5: Resilience and Sustainability Integration in Transportation and Spatial Planning Processes. (Source: Own Construction, 2017). 
Measurability of planning inputs and outputs is fundamental to ensure timeously interventions to guide strategy, planning processes and development by overcoming preconceived ideas such as ' $u$ ' and 'them' in theory and practice. An appropriate understanding of the application of adaptive capacity within spatial systems is thus fundamental. The research clearly demonstrates the need to rethink existing theories related to transportation and spatial planning and to align it with the discourse in resilience and sustainability thinking.

\section{REFERENCES}

[1] Elmqvist, T., Urban sustainability and resilience-why we need to focus on scales, available at http://thenatureofcities.com 2013 (accessed December, 2016).

[2] Eraydin, A. \& Taşan-Kok, T. (Eds). Resilience Thinking in Urban Planning, Springer Dordrecht Heidelberg, 2014.

[3] United Nations. Our Common Future. Report A/42/427. Our Common Future, Chapter 2: Towards Sustainable Development, available at www.un-documents.net/ocf-02.htm

[4] Olazabal, M., Chelleri, L., Waters, J.J. \& Kunath, A., Urban resilience: towards an integrated approach, 2012. Available at: https://www.researchgate.net/publication/236236994.

[5] Harrison, P., Bobbins, K., Culwick, C., Humby, T.L., La Mantia, C., Todes, A. \& Weakley, D., Urban resilience thinking for municipalities. Publication by University of the Witwatersrand and Gauteng City-Region Observatory (GCRO), Johannesburg, 2014.

[6] Meerow, S., Newell, J. \& Stults, M., Defining urban resilience: a review. Landscape and Urban Planning, 147(38), 2016.

https://doi.org/10.1016/j.landurbplan.2015.11.011

[7] United Nations, Sustainable development: from Brundtland to Rio. Document prepared by Drexhaage, J. \& Murhy, D., International Institute for Sustainable Development. United Nations Headquaters, New York, 2010.

[8] United Nations. Our Common Future. Report A/42/427, Our Common Future, Chapter 2: Towards Sustainable Development, 1986. Available at www.un-documents.net/ ocf-02.htm

[9] Holling, C.S., Resilience and stability of ecological systems. Annual Review of Ecology and Systematics, 4, pp. 1-23, 1973. https://doi.org/10.1146/annurev.es.04.110173.000245

[10] Holling, C., Gunderson, L. \& Ludwig, D., In quest of a theory of adaptive change. In Panarchy: Understanding Transformations in Human and Natural Systems, eds C.S. Holling \& L.H. Gunderson Washington, DC: Island Press, pp. 3-25, 2001.

[11] Davoudi, S., Resilience: a bridging concept or a dead end? Planning Theory and Practice, 13(2), 2012.

[12] Berkes, F., \& Folke, C. (Eds.). Linking Social and Ecological Systems: Management Practices and Social Mechanisms for Building Resilience, Cambridge: Cambridge University Press, 1998.

[13] Berkes, F., Colding, J. \& Folke, C. (Eds.), Navigating Social-Ecological Systems. Building Resilience for Complexity and Change, Cambridge University Press, 2003.

[14] Armitage, D.R. \& Johnson, D., Can resilience be reconciled with globalization and the increasingly complex conditions of resource degradation in Asian coastal regions? Ecology and Society, 11(1), 2003. Available at: http://www. ecologyandsociety.org/ vol11/iss1/art2/ 
[15] Walker, B.H., Anderies, J.M., Kinzig, A.P. \& Ryan, P., Exploring resilience in socialecological systems through comparative studies and theory development: introduction to the special issue. Ecology and Society, 11(1), 2006. Available at: http://www.ecologyandsociety.org/vol11/iss1/art12/

https://doi.org/10.5751/ES-01573-110112

[16] Gunderson, L. \& Holling, C.S., Panarchy: Understanding Transformation in Human and Natural Systems, Washington, DC: Island Press, 2002.

[17] Anderies, J.M., Janssen, M.A. \& Ostrom, E., A framework to analyze the robustness of social-ecological systems from an institutional perspective. Ecology and Society, 9(1), 2004. Available at: http://www.ecologyandsociety.org/vol9/iss1/art18 https://doi.org/10.5751/ES-00610-090118

[18] Resilience Aliance. Urban Resilience Research Prospectus: A Resilience Alliance Initiative for Transitioning Urban Systems towards Sustainable Futures. 2007. Available at: http://bit.ly/resilienceprospectus

[19] Folke, C., Carpenter, S.R., Walker, B.H., Scheffer, M., Elmqvist, T., Gunderson, L.H. \& Holling, C.S., Regime shifts, resilience and biodiversity in ecosystem management. Annual Review of Ecology and Systematics, 35(1), pp. 557-581, 2004.

https://doi.org/10.1146/annurev.ecolsys.35.021103.105711

[20] Peterson, G., Political ecology and ecological resilience: an integration of human and ecological dynamics. Ecological Economics, 35(3), pp. 323-336, 2000.

https://doi.org/10.1016/S0921-8009(00)00217-2

[21] Talvitie, J., Incorporating the Impact of ICT into Urban and Regional Planning European. Journal of Spatial Development, 2004. Available at: http://www.nordregio.se

[22] Plummer, R., Crona, B., Armitage, D.R., Olsson, P., Tengö, M. \& Yudina, O., Adaptive co-management: a systematic review and analysis. Ecology and Society, 17(3), 2012. https://doi.org/10.5751/ES-04952-170311

[23] Wilkinson, C., Social-Ecological Resilience and Planning: an Interdisciplinary Exploration, Stockholm University, University Press, Sweden, 2012.

[24] Fleischhauer, M., The role of spatial planning in strengthening urban resilience. Institute for Spatial Planning (IRPUT). Dortmund University of Technology. Dortmund. Germany. In H.J. Pasman \& I.A. Kirrilan (eds). Resilience of Cities to Terrorist and other Threads, Springer Science and Business Media. B.V, 2008.

[25] Pissourios, L.A., Top-down and bottom-up urban and regional planning: towards a framework for the use of planning standards. European Spatial Research and Policy, 21(1), 2014.

[26] Healy, P., Planning through debate: the communicative turn in planning theory. In Campbell, S. and Fainstein, S. (Eds.). Readings in Planning Theory, Massachusetts: Blackwell Publishers (originally published in 1992 in Town Planning Review, 63(2), pp. 143-162, 1996.

[27] Ahern, J.F., Cilliers, S. \& Niemela, J., The concept of ecosystem services in adaptive urban planning and design: a framework for supporting innovation. Landscape and Urban Planning, 125, pp. 254-259, 2014. https://doi.org/10.1016/j.landurbplan.2014.01.020

[28] Tress, B., Tress, G. \& Fry, G., Integrative studies on rural landscapes: Policy expectations and research practices. Landscape and Urban Planning, 70, pp. 177-191, 2005. https://doi.org/10.1016/j.landurbplan.2003.10.013 